\title{
Adhesin 49.4 Kda of Porphyromonas Gingivalis Outer Membrane Protein on Neutrophil
}

\author{
${ }^{1}$ Siti Nurul Mubarokah, ${ }^{2}$ I Ketut Gede Muliartha, ${ }^{3}$ Edi Widjajanto, \\ ${ }^{4}$ Sanarto Santoso, ${ }^{5}$ Sumarno Reto Prawiro \\ ${ }^{1}$ Laboratory of Biochemistry, Medical Faculty of Malang Islamic University Malang \\ ${ }^{2}$ Laboratory of Clinical Anatomy and Pathology, Medical Faculty of Brawijaya University Malang \\ ${ }^{3}$ Laboratory of Clinical Pathology, Medical Faculty Brawijaya University Malang \\ ${ }^{4}$ Laboratory of Microbiology, Medical Faculty of Brawijaya University Malang
}

\begin{abstract}
Abstrac: Periodontitis is caused mostly by Porphyromonas gingivalis ( $P$. gingivalis) and it relates to acute coronary syndrome. $P$. gingivalis readily invades into blood circulation and potentially induces collagenolytic activity of neutrophil which results in collagen vascular degradation and leads to atherosclerotic plague rupture (APR). Neutrophil has a role event in APR and is responsible for the occurrence of fatal cardiovascular events such as acute myocardial infarction (AMI). This information brought out notion concerning the adhesion interaction of P.gingivalis with neutrophil.

The aim of the study is to assess adhesion molecule of $P$. gingivalis outer membrane protein (OMP).

The study was done by partial characterization taken in hemagglutination assay using mice erythrocytes, adhesion inhibition assay by gradual concentration of adhesion blocked in neutrophil, immunologic assay using Western-blotting and immunocytochemistry.

The results showed that $49.4 \mathrm{kDa} P$. gingivalis OMP can agglutinate mice erythrocytes and adhere to netrophil. The increasing concentration of OMP $P$. gingivalis $49.4 \mathrm{kDa}$ reduces adhesion process to netrophil. This protein was recognized by the polyclonal antibody of $49.4 \mathrm{kDa}$ adhesion molecule.

It can be concluded that $49.4 \mathrm{kDa} P$. gingivalis outer OMP is a hemagglutinin and an adhesion molecule to netrophil.
\end{abstract}

Keywords: 49.4 kDa P. gingivalis OMP, neutrophil, hemagglutination, adhesin.

\section{INTRODUCTION}

Acute myocardial infarction (AMI), is the necrosis of the heart muscle caused by an imbalance between the demand and the supply of oxygen which occurs suddenly, and today the prevalence, mortality and treatment cost are still being a major health problem.

Porphyromonas gingivalis that invades easily into blood circulation is associated with the need to obtain nutrients. The component nutrients that are absolutely necessary as iron source are peptides and hemin. Because the main source of hemin is found in the blood hemoglobin, P. gingivalis tends to enter the blood circulation to get the hemoglobin [1]. Various studies have also reported that $P$. gingivalis has ability to invade and get stuck to the endothelium and atherosclerotic plaque (70-10). The attaching ability of $P$. gingivalis on cell is mediated by the adhesion molecules on the bacterial between molecule receptor on cell surface [2].

Bacterial adhesion and cell receptor molecules are different in molecular weight. The attachment of two molecules has to play in a role as adhesion bacteria to host cells. Many bacterial adhesion molecules are identical to the hemagglutinin protein. To corfirm that a bacterial molecule is molecule adhesion into host cell can be detected by counting of the Adhesion Index (AI). AI is an average number of bacteria that adhere to every cell which is counted in 100 cells [3,4].

Outer membrane protein (OMP) of a Gram negative bacteria including $P$. gingivalis, plays a significant role in the virulence process of adhesion into host cell. The molecules adhesion can contribute as an antigen.This antigen will produce antibody which could be detected in patients serum [5].

Previous studies have proven and revealed that the adhesion process $P$. gingivalis can be found on the surface of endothelial cells as well on atherosclerotic plaques. The allegations concerning the adhesion processes of $P$. gingivalis on neutrophil has not been reported. Further, this study would prove the existence of hemagglutinin protein on the bacterial OMP $P$. gingivalis suspected as one adhesion molecule on neutrophil. 


\section{Research Methods}

\section{Bacterial culture}

The sample was $P$. gingivalis Strain ATCC33277 obtained from Province of Laboratory Health Yogyakarta of Central Java. The culture was used by modifying the method of Condorelli. P. gingivalis was cultured in BHI medium and enriched with vitamin $\mathrm{K} 1$ and hemin, then cultured in an anaerobic atmosphere. $P$. gingivalis concentration was adjusted to $10^{8}$ per $\mathrm{ml}[6]$.

\section{Isolation of $\boldsymbol{P}$. gingivalis outer membrane protein (OMP)}

Isolation was carried out according from Evan's [7]. P. gingivalis in $500 \mathrm{~mL}$ of BHI media was precipitated and washed by using PBS pH 7.4, then added with $n$-Octyl- $\beta$-D-glucopyranoside (NOG) untill it reached $0.5 \%$ of the concentration and 1 minutes full speed vortex was used or homogenation. Subsequently, the solution was centrifuged at $12,000 \mathrm{rpm} 4^{\circ} \mathrm{C}$ for 15 minutes. The supernatant was collected as the first supernatant. Sediment then was resuspended by using NOG and the treatment was repeated for six times (six collections of supernatant). Dialysis process can be applied to all of the supernatant collections. For The first 24 hours we used $\mathrm{dH}_{2} \mathrm{O}$ and the process was continued by PBS pH 7.4 for the next $2 \times 24$ hours.

\section{Sodium dodecyl sulfate poliacrylamide gel electrophoresis (SDS-PAGE)}

Molecular weight monitoring was done by mean of SDS-PAGE, according to Laemmli method [8]. Protein sample was heated $100^{\circ} \mathrm{C}$ for 5 minutes in a buffer solution containing $5 \mathrm{mM}$ Tris $\mathrm{HCl} \mathrm{pH} 6.8,2-$ mercapto ethanol $5 \%$, w/v sodium dodecyl sulfate $2.5 \%, \mathrm{v} / \mathrm{v}$ glyserol $10 \%$, with bromophenol blue as color tracker. The gel was $12.5 \%$ mini slab gels (4\% gel tracking). The voltage was $120 \mathrm{mV}$. Coomassie brilliant blue was used for staining and pre stained protein ladder was used as the protein marker.

\section{Protein Purification of $P$. gingivalis OMP Hemaglutinin}

The proteins profile from the OMP collections was performed by SDS-PAGE. The gels were cut straight at the desired molecular weight, collected, and put into a dialysis membrane tube containing electrophoresis running buffer liquid. Electrophoresis used an electrophoresis apparatus horizontal (voltage of $125 \mathrm{mV}$ for 25 minutes). Then the result of electrophoresis was dialysized. The first 24 hours the dialisis used $\mathrm{dH}_{2} \mathrm{O}$ and continued with PBS pH 7.4 for the next $2 \times 24$ hours. Dialysate fluid of the SDS-PAGE protein band was precipitated using cold absolute ethanol. The precipitate was assessed by hemagglutination test.

\section{Hemagglutination Assay}

The hemagglutination test was done according to instruction from Hanne and Finkelstein [9]. The sample was diluted into concentration of $1 / 2$ in the microplate wells for each $50 \mu 1$ volume. Each well was added with suspension of red blood cell of mice at concentrations of $0.5 \%$. Further more was shaken in rotator plate for one minute and resided at room temperature for an hour. The titer was determined by the presence of red blood agglutination on the lowest dilution. The samples were whole-cell $P$. gingivalis lysat (intact bacterial cells) and the OMP was already prepared. The type of red blood cells was taken from healthy mice.

\section{Isolation of Neutrophil}

Neutrophil isolation was carried out by ficoll hypaque centrifugation method [10]. The heparinized whole blood $(10 \mathrm{ml})$ was divided into two tubes and diluted to PBS pH $7.4(1: 1)$. After that it was superimposed on ficoll hypaque (density 1.0770 and $1119 \mathrm{~g} / \mathrm{mL}$ at $\left.20^{\circ} \mathrm{C}\right)(1: 2)$ and centrifuged for 30 minutes, $1000 \mathrm{rpm}$, RT to form three layers. Buffy coat ring layer in the middle of the separated components then was diluted to PBS pH 7.4 and centrifuged for 10 minutes, $1500 \mathrm{rpm}$, RT. Pellets were washed 3 times with PBS pH 7.4 and neutrophil morphology was observed through Giemsa staining.

\section{Optimization of $\boldsymbol{P}$. gingivalis Incubation Time on Neutrophil}

The preparation of bacterial culture used $6000 \mathrm{rpm}$ centrifugation for 10 minutes. Supernatant was discarded and the $P$. gingivalis pellet was suspended with PBS. The sample was measured by optical density turbidity level $(\mathrm{OD}=1)$ or approximately $10^{8}$ cells $/ \mathrm{ml}$. Neutrophil cell suspension was poured into the bacterial suspension. The whole suspension was shaken in a water bath shaker in gradual time, from 30 seconds, 1 minute, 2 minutes, 5 minutes, 10 minutes, 30 minutes and 40 minutes.

\section{Adhesion Molecule Assay}

Temperature of $37^{\circ} \mathrm{C}$ was maintained with a 60 times shakes per minute. Each of $20 \mu \mathrm{l}$ suspension then was taken to make smear on object glasses. Neutrophil that had been prepared was inserted into the bacterial suspension as mentioned above. Suspension was shaken in a waterbath shaker for the optimum time at a temperature of $37^{\circ} \mathrm{C}$ with a staggering of 60 shakes/ minute. The pellet was collected and washed by using PBS as much as 3 time. Then it was suspended with $300 \mu \mathrm{l}$ PBS and each of $20 \mu \mathrm{l}$ suspension then was taken to 
Adhesin 49.4 Kda Of Porphyromonas Gingivalis Outer Membrane Protein On Neutrophil make smear on glass objects; stained by Giemsa and the adhesion index of $P$. gingivalis on neutrophil was observed by microscopy. It was stained by Giemsa staining and the adhesion index of $P$. gingivalis on neutrophil was calculated under microscopy [4].

\section{Adhesion Inhibitory Assay}

Adhesion inhibitory assay was modified from Nagayama [4]. The preparation of bacterial culture was taken for $50 \mu \mathrm{l}$ and centrifuged at $3500 \mathrm{rpm}$ for 10 minutes. Supernatant was discarded and the pellets of $P$. gingivalis was challenged to neutrophil that had been first covered with the HA protein in a $500 \mu \mathrm{l}$ dilution. Then it was shaken for the optimum time (minutes) $37^{\circ} \mathrm{C}$, with a staggering of 60 shakes/ minute. The sample was centrifuged at $1000 \mathrm{rpm}$ for 5 minutes and the pellet was suspended with $300 \mu \mathrm{l} \mathrm{PBS}$. Each of $20 \mu \mathrm{l}$ suspension then was taken to make smear on glass objects. After that it was stained by Giemsa and the adhesion index of $P$. gingivalis on neutrophil was observed by microscopy.

\section{Production of polyclonal antibody of $P$. gingivalis OMP adhesin}

The $100 \mu \mathrm{g} / \mathrm{ml}$ antigen were prepared by mixing it with the incomplete adjuvant (Incomplete Freund 'adjuvant) 1:1 before injecting it intraperitoneally in male mice. Boosters were given every once a week for three weeks with complete adjuvant (complete Freund 'adjuvant). Mouse blood serum containing polyclonal antibodies was harvested three days after the last booster.

\section{Imunocytochemistry}

The sample of $P$. gingivalis adhesion molecule of OMP on neutrophil cells was fixated with methanol. Than it was followed by washing 3x with PBS pH 7.4, induced with 3\% hydrogen peroxidase for 10 minutes. After that it was washed with PBS pH 7.4 for 5 minutes and repeated for three times. The process was followed by incubation with blocking buffer (containing $0.2 \% \mathrm{BSA}, 0.2 \% \mathrm{NaN}_{3}, 1 \%$ Triton $\mathrm{X}-100$ ) for 1 hour at room temperature. Then sample was washed with PBS pH 7.4 for three times. The next step was incubation with primary antibodies (polyclonal antibody production of $P$. gingivalis) with a ratio of $1: 50 \mu \mathrm{l}$ for overnight at $4^{\circ} \mathrm{C}$. Subsequently it was washed with PBS 3x for 5 minutes and incubated with secondary antibody of anti-mouse IgG for 1 hour (1:200). Further it was washed with PBS 3x 5 minutes, dropped with streptavidin HRP (1:500) as much as $50 \mu \mathrm{l}$ for each (for 45 minutes) and washed using PBS 3x for 5 minutes, and finally incubated with DAB (diaminobenzidine) for 30 minutes. Then immediately it was poured with HE (Meyer hematoxyline) for $10 \mathrm{~min}$ and terminated with water dripping faucet directly for 10 minutes. After dried, the prepared samples were observed under the microscope [11].

\section{Statistical Analysis}

Data of the adhesion and inhibition was analyzed with linear regression. One-way ANOVA and Tukey's test was used to detect differences in the HA protein inhibition of $P$. gingivalis on neutrophil cells based on the increased concentration of HA protein.

\section{Results}

Preliminary assay to determine the time of $P$. gingivalis incubation time with neutrophil was done before the adhesion assay of $P$. gingivalis on neutrophil. It considers here that the adhesion test would not be performed in anaerobic conditions which was the most suitable for $P$. gingivalis.

The number of bacterial adhesion index continues to increase along with the addition of incubation time and no longer experiences a significant increase after 30 minutes incubation. Performance of adhesion index increase was shown in Fig. 2.

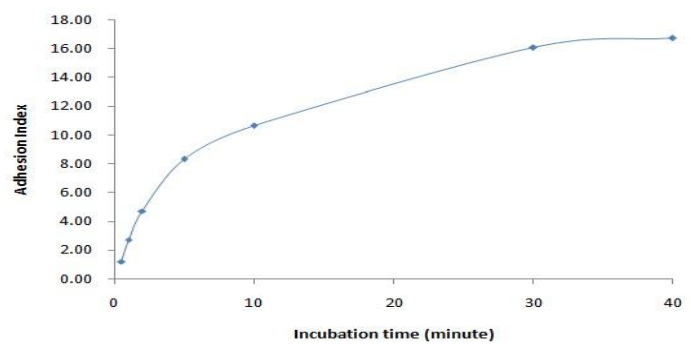

Figure 2. P. gingivalis Adhesion index Based on Incubation Time

\section{Adhesion Assay of $\boldsymbol{P}$. gingivalis on Neutrophil}

Preparation was viewed under a microscope with 1000x magnification to see the type of attachment and calculate the index of adhesion (Fig. 3). 


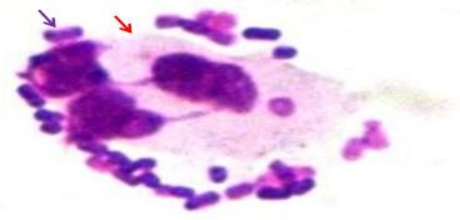

Figure 3. P.gingivalis on neutrophil adhesion

Giemsa staining (magnification $1000 \mathrm{x}) \rightarrow$ P.gingivalis $\rightarrow$ neutrophil

In Fig. 3 above it can be seen that the type or profile P.gingivalis bacterial adhesion to neutrophil cell was a type of diffusion or spread.

\section{Isolation of OMP Hemaglutinin Protein of Porphyromonas gingivalis}

The isolated OMP of P.gingivalis collection (six times isolation) was profiled by using electrophoresis method to determine the molecular weight (MW) protein in OMP (Fig. 4).

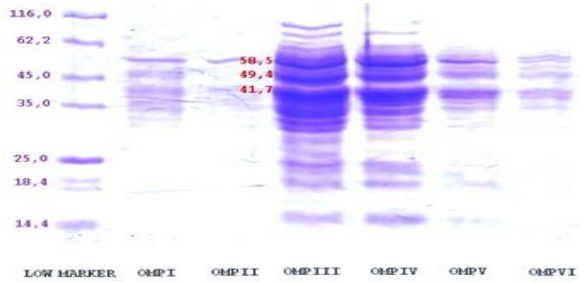

Figure 4. Separation Protein Profile of the Outer Membrane Protein (OMP) P. gingivalis of SDS-PAGE electrophoresis with Commasie Blue Staining.

The OMP was isolated from $P$. gingivalis by using NOG in sixth time separation. The first result was isolated OMP I, the second was isolated the OMP II and was finished until the sixth was isolated OMP VI. Marker proteins was used protein marker ladder (Sigma). Protein molecular weight was in the unit of kDa.Fig. 4 showed three major proteins of the proteins with molecular mass of $58.5 \mathrm{kDa}, 49.4 \mathrm{kDa}$ and 41.7 $\mathrm{kDa}$. Furthermore, each of the collection passed through hemagglutination test using mice erythrocytes after purification by using electroelution. The Hemagglutination profile was presented in Fig. 5 .

Fig. 5 showed that the third OMP isolate provided the best aglutinat by mean of no protein deposition in the bottom of wells (dotting). Hemagglutination assay of those proteins was shown in Fig. 6. Aglutinat of the third OMP collection was at the highest titer (protein dilution 1/32) compared with other collections. The third collection protein $49,4 \mathrm{kDa}$ of OMP would be used as a sample for subsequent study.

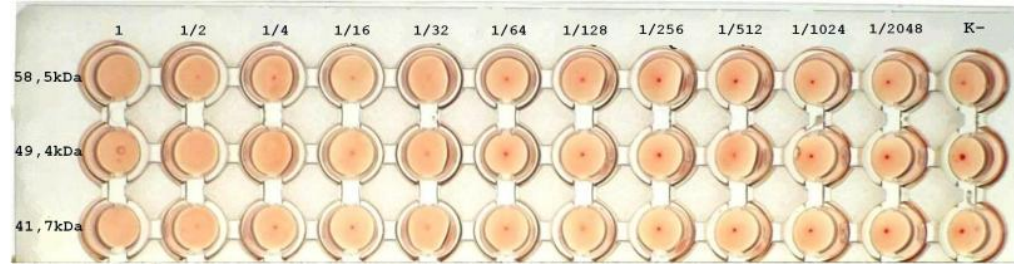

Figure 6. Hemagglutination Profile of Three Major OMP III Protein of P. gingivalis $(58.5 \mathrm{kDa}, 49.4 \mathrm{kDa}$ and $41.7 \mathrm{kDa})$.

The result of the hemagglutination assay (Fig. 6) showed that the three proteins were the hemagglutinin protein. The highest titer agglutination was the proteins OMP P. ginggivalis of $49.4 \mathrm{kDa}$.

\section{Inhibitory Assay of $P$. gingivalis adhesion on Neutrophil by Hemagglutinin OMP of 49.4 kDa}

According to the results of SDS-PAGE, purification of protein by using electroelusion method and continuation of the HA of the protein OMP P. ginggivalis of $49.4 \mathrm{kDa}$ is hemaglutinin. HA positive gave an important information that the protein is an adhesion molecule on neutrophil. The assessment was carried out by assigning the adhesion of $P$. gingivalis on neutrophil after blocking hemagglutinin protein which was made by gradual concentration of $100 \% ; 50 \% ; 25 \% ; 12.5 \% ; 6.25 \%$ and $3.125 \%$. 

The result of adhesion $P$. ginggivalis by blocking with protein HA 49.4 kDa on neutrophil can be seen in Fig. 7 .

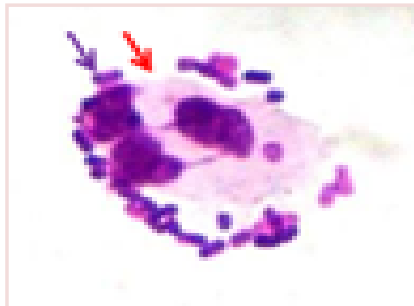

Figure 7. In OMP

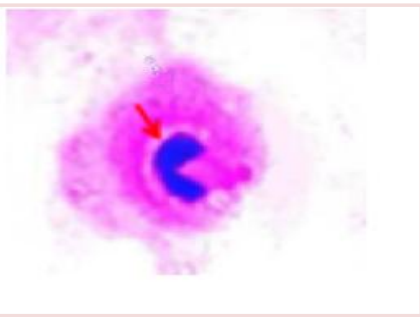

on on Neutrophil by Hema

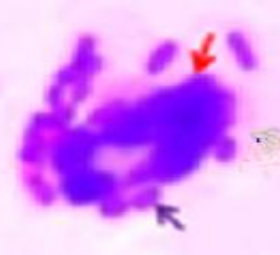

C

in $49.4 \mathrm{kDa}$ of $P$. gingivalis

Fig. 7.A showed the adhesion of $P$. gingivalis on neutrophil without 49.4 kDa OMP blocking. Fig.7.B and 7.C images showed differences in adhesion index of $P$. gingivalis due to inhibition by $49.4 \mathrm{kDa}$ OMP in the dilution of $100 \%$ and $3.125 \% . \rightarrow P$. gingivalis $\rightarrow$ Netrophil. Giemsa staining (magnification $1000 \mathrm{x}$ ).

Statistical analysis of Inhibitory Assay of P. gingivalis adhesion on neutrophil by hemagglutinin OMP of 49.4 $\mathrm{kDa}$ justified that the protein $49.4 \mathrm{kDa}$ OMP $P$. ginggivalis is an adhesin. The higher protein hemagglutinin of concentration will block higher of $P$.gingivalis adhesion, which was shown from the less attached $P$. gingivalis on neutrophil. The result of decreasing $P$. gingivalis adhesion was also supported by regression analysis and bar charts presented in Fig. 8.

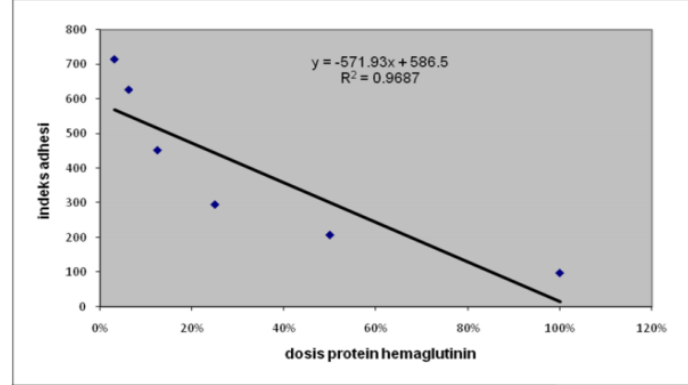

Figure 8. Linear Regression of $P$. gingivalis Index Adhesion in Gradual Dilution of protein Hemagglutinin 49.4 $\mathrm{kDa}$ OMP

Adhesin of OMP P. gingivalis $49.4 \mathrm{kDa}$ above then was characterized the immunogenicity by administration into mice to get the immune response (polyclonal antibody production) and clarified the result by immunoblotting using Western-blotting methods and Immunocytochemistry.

\section{Detection of Anti-adhesin of OMP P. gingivalis $49.4 \mathrm{kDa}$}

Immunologic characterization was aimed to find out the antigenicity in inducing humoral immune responses. Immunoblotting resulted by Western-blotting of subunit protein $49.4 \mathrm{kDa}$ of OMP P. gingivalis challenged with rich serum IgG anti protein hemagglutinin $49.4 \mathrm{kDa}$ OMP $P$. gingivalis (data not shown)

The antibody response to antigen of adhesin OMP $P$. gingivalis $49.4 \mathrm{kDa}$ was also proved through immunocytochemistry techniques. The results showed rich serum $\mathrm{IgG}$ anti protein hemagglutinin $49.4 \mathrm{kDa}$ OMP P. gingivalis gave a positive reaction to the antigen (adhesin of OMP P.gingivalis $49.4 \mathrm{kDa}$ ) that has been overlaid on neutrophil (Fig. 10, it can be seen that the neutrophil membrane around the cell covered the by protein hemagglutinin $49.4 \mathrm{kDa}$ OMP $P$. gingivalis).

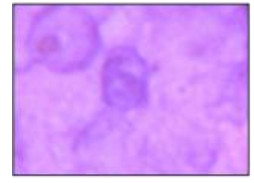

A

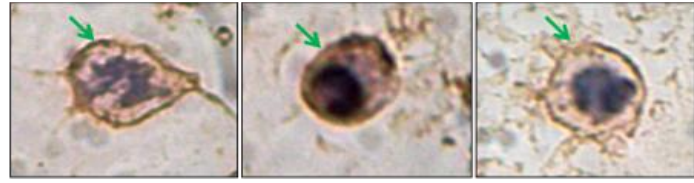

B

Figure 10. Test results imunologic P.gingivalis $49.4 \mathrm{kDa}$ adhesin protein with IgG Mice injected with $P$. gingivalis $49.4 \mathrm{kDa}$ adhesin protein.

Fig. 10.A showed negative immunocytochemistry result of neutrophil antigen with the overlaid bovine serum albumin. Figure 10.B showed positive immunocytochemistry result of neutrophil antigen coated with $P$. ginggivalis $49.4 \mathrm{kDa}$ adhesin $(\rightarrow$ adhesin of $P$. ginggivalis $49.4 \mathrm{kDa})$. 


\section{Discussion}

The result of this study found that the optimum time for $P$. gingivalis to effectively attach to the receptors on neutrophil is about 30 minutes. At this time interval, there were 16.08 of $P$. gingivalis adhered to neutrophil, and the addition time up to 40 minutes did not provide additional means on the number $P$. gingivalis attached to the neutrophil. This result was supported by Fig. 2 which showed that the graph began to remain constant after 30 minutes. This time incubation finding then next would be used in doing $P$. gingivalis adhesion on neutrophil.

There are some explanations regarding this result, first is that after 30 minutes $P$. gingivalis ability to tolerate the presence of oxygen decreased or even $P$. gingivalis was no longer active, the second is that after 30 minutes the neutrophil receptors that bind to the adhesin of $P$. gingivalis already saturated and glued by this bacteria. In this case, further research is needed to support and prove more allegations which were given from data obtained in this research.

Adhesion of $P$. gingivalis on neutrophil was conducted to evaluate the ability and the type of $P$. gingivalis adhesion on human neutrophil. In Fig. 3 it can be seen that $P$. gingivalis has the ability to adhere to neutrophil of healthy human blood and the type of observed bacteria adhesion belongs to diffuse type. Adhesion of diffuse type characterized from the bacteria spreads around the cell surface.

The ability of P.gingivalis adhesion on neutrophil is important as the basis for the isolation of its adhesin in order to evaluate the inhibition of bacterial adhesin against the bacteria adhesion on neutrophil.

Porphyromonas gingivalis ability to attach its receptor on neutrophil was in line with several studies which showed its ability inherent to a particular cell or substrate. Although many studies did not describe the type of the adhesion, but Hiratsuka in 1996 showed how P. gingivalis was inherent in oral epithelial cells through the mediation of the outer membrane protein. This finding also was suported by other studies that also found $P$. gingivalis was able to adhere to endothelial cells of human blood circulation [2, 9, 12, 13, 14, 15].

Lamont \& Jenkinson who explained $P$. gingivalis adhesion to a cell or substrate through its OMP by afimbrial adhesion, further proved that the bacterial aggregation of $P$. gingivalis and its co-aggregation to other bacteria are mediated by its OMP [1].

In this study, the $P$. gingivalis OMP was isolated using NOG as the cell membrane detergent of concentration $0.5 \%$ as mentioned by Zhang [16]. NOG is the best detergent with optimal selectivity in separating the cell protein membrane. The detergent dissolved membrane very effectively and could be easily separated through dialysis.

Several studies have shown some different OMP profiles, compared to what was found in this study. The protein with MW of $43 \mathrm{kDa}$ has been found from OMP P. gingivalis [17]. Then the protein with MW 40 $\mathrm{kDa}$ also has been discovered [18]. Furthermore the presence of $49 \mathrm{kDa}$ protein in the OMP has been found as well as in this study[19,20].

In order to prove if the separated proteins of $P$. gingivalis OMP are the hemagglutinin, the three main proteins were assigned by the hemagglutination test. Based on the data presented in Fig. 6, it showed that the $49.4 \mathrm{kDa}$ protein had the highest titer than the two others $(58.5 \mathrm{kDa}$ and $41.7 \mathrm{kDa})$. These results suggested that the $49.4 \mathrm{kDa}$ OMP had the best ability to agglutinate mice erythrocytes. It means that biological characteristics of the protein have many more similarities to the erythrocyte receptors.

In regards to $P$. gingivalis ability to agglutinate red blood cells, Hiroaki (2004) explained that this organism has a protein called hemagglutinin as a ligand [21]. The attachment by ligand is not only on cells in gingival tissue, but the same ligand is also used to stick on red blood cells and lysis the cell to take its hemin for bacterial nutritional requirements [18]. Based on the description above, the protein of $49.4 \mathrm{kDa} P$. gingivalis OMP discovered in this study might be simply as a hemagglutinin.

Outer Membran Protein $49.4 \mathrm{kDa} P$. gingivalis as a hemagglutinin ensured its role as an adhesion to neutrophil. It was determined by calculating the index of adhesion, which is the number of bacteria attached to each neutrophil and calculated on 100 cells. And in order to prove the role of $P$. gingivalis OMP hemagglutinin as an adhesin, hemagglutinin was used in adhesion inhibition assay of $P$.gingivalis on neutrophil. Inhibition was done by saturating the neutrophil receptors involved in the adhesion process with hemaggllutinin so that there would be an inhibition process of $P$. gingivalis adhesion .

In this study, the hemagglutinin inhibition assay was conducted by six variation of hemagglutinin concentration. These results lead that the hemagglutinin of $49.4 \mathrm{kDa} P$. gingivalis OMP is an adhesin to neutrophil. The same result shows that it presumably had a specific receptor of erythrocyte which can specifically bind to this hemagglutinin. Difference in MW explained that the proteins of $40 \mathrm{kDa}$ OMP was found to inhibit $P$. gingivalis adhesion and colonization of bacteria $P$. gingivalis [21].

The inhibitory adhesion assay by $49.4 \mathrm{kDa}$ of $P$. gingivalis OMP adhesion was shown at Fig. 7 . The adhesion appeared to surround the neutrophil membrane These data were supported by the immunocytochemistry assay of neutrophil against the adhesin (Fig. 10). Fig. 10 showed brown imaging evenly across the surface of neutrophil which was analyzed as the type of adhesion, and it is in line with the type of bacteria adhesion of Fig. 3 (without the protein coating). It could be understood that the adhesin would take the 
Adhesin 49.4 Kda Of Porphyromonas Gingivalis Outer Membrane Protein On Neutrophil neutrophil receptor right after coating. The receptor is the same one in which P.gingivalis is used to attach to the neutrophil (Fig.7) and higher concentration of the adhesin resulted in fewer bacteria that attached (Fig.7).

Study in vitro revealed that inhibition of $P$. gingivalis adhesion on neutrophil gives a significancy related to its ability to induce neutrophil collagenolytic activity in the mechanism of the inducing atherosclerotic plaque rupture [2]. The discovery of $P$. gingivalis adhesin proteins which could block the bacteria adhesion on neutrophil brings hope of this protein to be used as a vaccine to induce host active immunity. The monoclonal antibodies $P$. gingivalis adhesin that could be created as passive immunization may prevent the activation of degradative enzymes of neutrophil It also prevents the bacteria invasion to the epithelial cells. Bacterial invasion to epithelial cells is modulated by fibronectin. This step is a non specific defensive mechanism which involves many cells and molecules. The next step covers a more specific interaction of bacterial proteins, which is the interaction to other receptors resulting in a higher affinity to the host cell interaction, which leads in internalization of the bacteria by the host cells. Here, the presence of antibodies that could block $P$. gingivalis adhesion will reduce its patogenicity. This requires further research.

Previous study related to immunization by using protein of $P$. gingivalis OMP has been done [5]. The study explained that transcutaneous immunization with $40 \mathrm{kDa} P$. gingivalis OMP gave a good IgG response in serum and saliva. The antibodies produced from $P$. gingivalis $40 \mathrm{kDa}$ antigen also proved to be able to prevent aggregation and coaggregation of other bacteria that are disease causing pathogens in periodontitis. The research results bring hope to the method in preventing infection of $P$. gingivalis which has become an important systemic infection problem.

\section{Conclusion}

The $49.4 \mathrm{kDa}$ of $P$. gingivalis OMP was an molecule hemagglutinin that has ability to agglutinate mice erythrocytes. It has also demonstrated that the molecule hemagglutinin $P$. gingivalis was adhesin on neutrophil.

\section{References}

Lamont RJ., and Jenkinson HF. 1998. Life Below the Gum Kolom: Patogenic Mechanism of Porphyromonas gingivalis. Microbiology ang Molecular Biology Review. 62 (4). p. 1244-1263.

[2] Deshpande RG., Khan MB., Genco CA. 1999. Invasion of Aortic ang Heart Endothelial Cells by Porphyromonas gingivalis. Infection and Immunity. 1999; 66(11): 5337-5343.

[3] Todar K. The Mechanisms of Bacterial Patogenicity. Departement of Bacteriology. University of Wisconsin; 2002

[4] Nagayama, K., Oguchi, T., Arita, M., Honda, T. Purification and Characterization of a Cell Associated Hemagglutinin of Vibrio parahaemolyticus. Infec. Immun. 1995; 63(5) : 1987-1992.

[5] Maeba Satomi, Shigeo Otake, Jun Namikoshi, et al. 2005. Transcutaneous Immunization with a 40-kDa Outer Membrane Protein of Porphyromonas gingivalis Induces Specific Antibodies which Inhibit Coaggregation by P. gingivalis. J Vaccine. 2005;23:25132521

[6] Condorelli F., Scalis G., Cali G., Rosseti B., Nicoletti and Blue AML. 1998. Isolation of Porphyromonas gingivalis and Detection of Immunoglobulin A Specific to Fimbrial Antigen in Gingival Crevicular Fluid. JCM. 1998; 36(8): 2322-2325.

[7] Evans, D.G. and Evan, D.G. Y.R. 1978. New surface-associated heat-labil colonization factor antigen (CFA/II) produced by Enterotoxigenic Eschertichia coli sero groups O6 and O8. Infect. Immun 21:638-647.

[8] Laemli, UK. 1970. Cleavage of structural protein during the assembly of the head of bacteriophage T4. Nature.:680-686

[9] Hanne, L.F. and Findkelstein, R.A. 1982. Characterization and distribution of the hemagglutinins pruduced by Vibrio cholerae. Infect. Immun. 36:209-214.

[10] Romanelli R., Mancini S., Laschinger C., Overall CM., Sodek J., McCulloch CAG. Activation of Neutrophil Collagenase in Perodontitis. Infection and Immunity. 1999; 69(5):2319-2326.

[11] Sumarno RP, Yanuhar U, Winarsih S, Islam S and Santoso S. 2012. Detection of molecule adhesion sub-unit pili 48 kDa Salmonella Typhi by immunochemistry method using sera patients suffering from typhoid fever. J. Basic. Appl. Sci. Res (Accepted for publication)

[12] Dorn BR., Dunn WA., Fox AP. Invasion of Human Coronary Artery Cells by Periodontal Patogens. Infection and Immunity. 1999; 7(11): 5792-5708.

[13] Chiu B. Multiple Infection in Carotid Atherosclerotic Plaques. Am Heart J. 2001;138(5 Pt 2): 534-6.

[14] Haraszthy VI., Zambon JJ., Trevisan M., Zeid M., Genco RJ. Identification of Periodontal Patogens in Atheromathosus Plaques. J. Periodontol. 2000;71:1554-60.

[15] Stelzel M., Conrads G., Pankuweit S., Maisch B., Vogt S., Moosdorf R., Flores-de-Jacoby L. 2002. Detection of Porphyromonas gingivalis DNA in aortic Tissue by PCR. J. Periodontol. 2002 Aug;73(8):868-70.

[16] Zhang G, Neubert. Use of Detergent to Increase Selectivity of Immunoprecipitation of Tyrosine Phosphorilated Peptides Prior to Identification by MALDI Quadrupole-TOF MS. Proteomics. 2006; 6(2):571-8

[17] Hiratsuka K, Yoshida W, Hayakawa M, Takiguchi H, Abiko Y. Polymerase Chain Reaction and An Outer Membrane Protein Gene Probe for The Detection of Porphyromonas gingivalis. FEMS Microbiol Lett. 1996;138(2-3):167-72.

[18] Mouton C, Ni ED, Deslauriers M, Lamy L. The Hemagglutinating Adhesin HA-Ag2 of Bacteroides gingivalis is Distinct from Fimbrilin. Oral Microbiol Immunol. 1991;6(1):6-11

[19] Lepine J., Messner HA. progenitors (CFU-GEMM) in chronic myelogenous leukemia. The International Journal of Cell Cloning Pluripotent hemopoietic. 1996; 1(4):230-239

[20] Progulske-Fox, A., S. Tumwasorn, and S. C. Holt. The Expression and Function of a Bacteroides gingivalis Hemagglutinin Gene in Escherichia coli. Oral Microbiol. Immunol. 1989;4:121-131.

[21] Hiroaki, Tagawa, Kiyama K, Michiko, Sheng YL, Abiko Y. Inhibitation of Hemagglutinating Activity by Monoclonal Antibody Againts Porphyromonas gigivalis 40-kDa Outer Membrane Protein. Hybridoma and Hybridomics. 2004;23(3) 